\title{
MAPPING SOCIAL INNOVATION MAPS The State of Research Practice across Europe
}

\author{
Dr. Bastian Pelka \\ Social Research Centre - Central Scientific Institute of Technische Universität Dortmund, Germany \\ Dr. Judith Terstriep \\ Institute for Work and Technology, Westphalian University of Applied Sciences Gelsenkirchen, Germany
}

\begin{abstract}
In an effort to better understand the various forms of social innovation, mapping has become a common and widely applied method for gaining insights into social innovation practices. The transdisciplinary nature of social innovation research has led to a plurality of distinct approaches and methods. Given the increasing interest in social innovation, and the apparent endeavour among policymakers to utilise social innovation to address current societal challenges, it is argued that mapping efforts need to be streamlined in order to make better use of their results. The article describes 17 ongoing or recently finalised research projects on social innovation and their methodological approaches on "mapping" social innovations. It provides a systematic overview on project objectives, SI definitions and mapping approaches for each of the scrutinised projects and ends with a synoptical analysis on methods, objectives and missing research.
\end{abstract}

Keywords: Social Innovation, Mapping, Europe, Data Collection, Methodology.

Acknowledgements: This paper builds on the results of the research project SIMPACT - «Boosting the Impact of Social Innovation in Europe through Economic Underpinnings«. SIMPACT has received funding from the EU's 7th Framework Programme for research, technological development and demonstration under GA No. 613411.

\section{Introduction}

$\mathrm{T}$

The concept of "social innovation" has dramatically gained attention on the research and policy agenda in recent years. But though high expectations are bound to the idea of social innovation, the term itself and the conditions under which social innovations emerge and flourish, are still to be explored and 'there is still no theoretically grounded concept that is suitable for empirical research' (Howaldt, Kopp, Schwarz, 2015: 10).

Jane Jenson and Denis Harrison (2013: 7) have taken stock of different notions of social innovation, the use of this concept in research projects, the ongoing work on theory building and dissemination activities and suggest 'useful cross-level discussion among projects should be encouraged.' This is where this article starts.

This article scrutinizes several EU funded projects on social innovation for their methodology. As a result of the still unknown conditions of this topic, ongoing research activities aim at understanding the concept by description of its phenomena. Along this insight we scrutinized the ongoing research for descriptive methods, because initial research showed that many project have in common that they have started mapping cases of social innovation recently. 'Mapping' within these projects refers to a variety of understandings of visualization - not all of them apply a spatial dimension, but envisage to 'map' qualitative aspects of the observed social innovations. This paper describes some of these 'social innovation maps' and brings together quite different visualisations, observation dimensions and notions of social innovation. It reveals different Cartesian cat- egorizations and notions of 'mapping' - and of what counts as a 'social innovation'.

We start the discussion with an introduction of the distinct 'mapping approach' and the underlying understanding of 'social innovation'. The main goal is to provide an overview of the approaches currently applied. This review is, however, not all-encompassing because of the many initiatives that are not documented; rather this article serves the purpose of exemplifying and explaining the trend towards mapping as well as the consequence for future research.

The need to substantiate policy and practice by evidence is an emerging theme in social innovation. Although a growing body of examples of successful and less successful social innovations exists, these are rather scattered and cover an array of diverse aspects. ${ }^{1}$ Today's challenge seems to be the combination of visualising social innovation phenomenons and to quantify or qualify their impact. ${ }^{2}$

\section{Variety of Mapping Approaches}

Based on the above considerations, identified mapping activities will be introduced to exemplify the distinct approaches applied including the underlying understanding of social innovation. Being aware of the multiplicity of

\footnotetext{
$1 \quad$ Cf. http://siresearch.eu/blog/measuring-and-mapping-socialinnovation

2 Cf. https://www.ashoka.org/files/ICT-Based-Social-Impact 092014-report.pdf
}

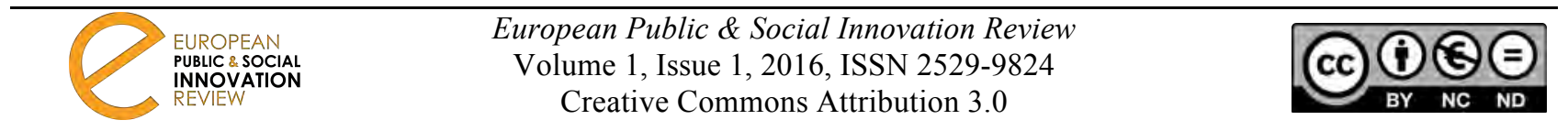


ongoing mapping activities across Europe and beyond, the authors collected a variety of recent mapping exercises in this thematic field. To identify a base of projects to be scrutinised, the following selection criteria were applied: (1) activities funded under FP7 which are (2) ongoing respectively did not end later than twelve months earlier. This lead to the identification of 17 projects which are introduced in the following.

\subsection{SIMPACT}

The project. «Boosting the Impact of Social Innovation across Europe through Economic Underpinnings» (SIMPACT) has a twofold objective: It asks for the economic factors that underpin social innovation's social and economic impact, while emphasising social innovation's role in empowering vulnerable groups in society. Substantiating the economic dimensions of social innovation as a so far largely unexplored research field is expected to accelerate the social and economic impact of social innovation through an advanced knowledge base and tailored tools supporting policymakers, innovators, investors and intermediaries.

Definition of social innovation. According to SIMPACT's rational, social innovation is referred to as ' $[\ldots]$ novel combinations of ideas and distinct forms of collaboration that transcend established institutional contexts with the effect of empowering and (re)engaging vulnerable groups either through the innovation process or as a result of it' (Terstriep et al., 2015: 6).

Mapping approach. In an initial step a «Multidisciplinary Literature Review» was conducted which laid the foundation for a concept to help identify the numerous factors that underlie economic and social impacts. Subject to an iterative process of theorising and evidence collection, the theoretically deduced categories and related hypotheses on economic components (actors, resources, institutions), objectives (social, economic, political) and principles (mode of efficiency and governance) build the point of departure for the empirical work. With the aim to establish strong synergies between the production of theory, strategy and appropriate methodologies, the evolutionary character of social innovations and its dynamics are reflected in the distinct forms and levels of analysis: Meta-analysis of existing social innovation cases - identifies through online repositories such as Ashoka or Innoserv - have been combined with Business Case Studies (BCSs) and Social Innovation Biographies (SIBs). The broad meta-analysis of existing cases, which captures multifaceted aspects of social innovation, was substantiated by in-depth analysis of specific economic factors. According to the project's rational, in an initial step two filters were applied to scan existing databases for relevant cases: firstly, distinct welfare regimes across Europe and secondly, fields of action, namely employment, migration and demographic change, as well as gender, education and poverty as transversal themes. The latter also constituted the unifying elements of cases across the distinct levels and foci of analysis. In total 94 social innovation cases were collected and documented in ID Cards, which summarise the basic information for each case. Meta-analysis in the form of a «qualitative comparative analysis» (QCA) was conducted for all 94 cases to identify metacomponents, -objectives and-principles across the defined fields of action (horizontal analysis). In addition, patterns of social innovation were derived for each field of action (vertical analysis). These were compared across the distinct welfare regimes.

Figure 1. SIMPACT Map of Business Case Studies \& Social Innovation Biographies.

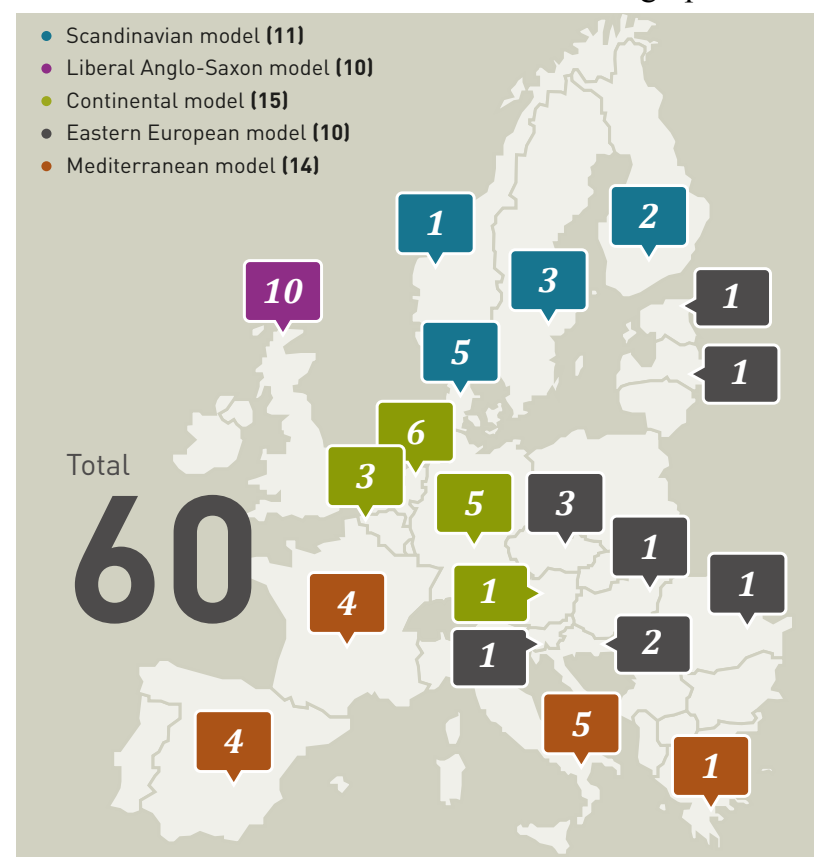

Source: Terstriep et al. (2015). 
Applying qualitative desk research, which made use of information from different sources (e.g. scientific publications, interviews, presentations, websites etc.), 26 BCSs were conducted to gain a better understanding of the social innovation ecosystem, value chains and business opportunities. By carrying out 34 SIBs the project applied a new methodology that enabled capturing the development paths, knowledge trajectories and stakeholder interactions throughout the innovation processes, from ideation to implementation. Following the process of creation with narrative interviewing methods and triangulation, the biography of an innovation is reconstructed including its components, objectives and principles. This leads to a better understanding of the spatial, social and temporal trajectories in the rise and spread of Social Innovations.

\subsection{CrESSI}

The project. «Creating Economic Space for Social Innovation» (CrESSI) explores the economic underpinnings of social innovation with a particular focus on how policy and practice enhance the lives of the most marginalised and disempowered citizens in society. Although research within CrESSI and SIMPACT cover the same topic, they complement each other due to their distinct theoretical frameworks.

Definition of social innovation. CrESSI understands social innovation ' $[. .$.$] as the development and delivery$ of new ideas and solutions (products, services, models, markets, processes) at different socio-economic levels that intentionally seek to change power relations and improve human capabilities, as well as the process via which these solutions are carried out' (Houghton Budd, Naastepad \& van Beers, 2015: 3).

Mapping approach. CrESSI takes stock of examples of social innovations, including both historic and recent, as well as both successful and less successful ones. Building on the project's 'Extended Social Grid Model' (Nichols \& Ziegler, 2015), which combines Beckert's (2010) 'Social Grid Model' with the 'Capabilities Approach' of human development and empowerment (Sen \& Nussbaum, 2009) and Mann's (2013) 'Power' approach, social innovations across Europe are examined in longitudinal and historical studies.

\subsection{SI-DRIVE}

The project. Social Innovation - Driving Change (SIDRIVE) strives to (1) determine the nature, characteristics and impacts of social innovation as key element of a new paradigm of innovation, (2) to map, analyse and promote social innovation in Europe and world regions to better understand and enable social innovations and their capacities in changing societies, (3) to identify and assess success factors in seven policy areas and to (4) undertake future-oriented research.

Definition of social innovation. Within SI-DRIVE social innovation is understood as '[...] a new combination of social practices in certain areas of action or social contexts with the goal of better satisfying or answering social needs and problems than is possible on the basis of existing practices' (Howaldt et al., 2014: 3).

Mapping approach. The overall aim of the project's mapping is to compare European approaches with global regional approaches, analyse the different approaches and priorities, as well as to identify good practice and lessons learnt. Hence, SI-DRIVE conducts the mapping in two steps - an initial mapping («baseline mapping») by means of desk research captures basic information about 1'000 actual social innovations in seven policy fields ${ }^{3}$ from secondary data sources, leading to a typology of SI. Case screening used country-coverage (Europe, world-regions), aligned with the definition of social innovation and corresponding to defined policy fields as a selection criteria. Based on the project's five key dimensions of social innovation ${ }^{4}$ from the 1'000 cases the 300 most important («prototypical») cases are chosen as basis for selection of 70 cases for in-depth analysis. Throughout the data collection it is distinguished between the micro-level of single projects/initiatives and the mesolevel of practice fields. Whilst projects/initiatives refer a single concrete implementation of a solution, a practice field expresses general characteristics common to different projects/initiatives.

\subsection{TRANSIT}

The project. Overall aim is to develop a Transformative Social Innovation Theory (TRANSIT) of middlerange with a focus on empowerment and change in society that is both relevant and practical. Structured around the four thematic areas of governance, social learning, funding and monitoring, the project considers the micro-level of local and transnational initiatives in Europe and Latin-America as well as the role of macro trends in society (e.g. financial crisis, climate change, ICT-revolution), referred to as 'game changers'.

Definition of social innovation. Transformative Social Innovation (TSI) is conceptualised as a non-linear interaction between social innovation (micro-level), system innovation (meso-level) and game changers as exogenous developments at the macro-level. Social innovation is understood as ' $[. .$.$] new services, practices or ideas at$ the micro-level of «niches»', whereas system innovation refer to change of dominant institutions and practices, i.e. 'regimes' (Avelino et al., 2014).

Mapping approach. The mapping of TSI cases is lead by the research question, how social innovation interacts with other forms of (transformative) change, and how actors are empowered therein. Units of analysis are local initiatives and transnational networks. TRANSIT's map-

\footnotetext{
${ }^{3}$ SI-DRIVE has defined the following policy fields: education, employment, environment, energy, mobility / transport, health and social care, poverty and sustainable development.

4 SI-DRIVE's five key dimensions are concepts, social need, resources, governance/actors and process dynamics (Howaldt et al., 2014).
} 
ping is based on an embedded case study approach that combines qualitative in-depth case study analysis with «quali-quantative comparative meta-analysis» (Søgaard Jørgensen et al., 2014). Initially, in-depth case studies of 20 transnational networks - that work on social innovation to co-create new social practices with the aim to contribute to societal transformation - plus 40 local manifestations in Europe and Latin America were conducted. These have been classified according to the three transformative discourses «New Social Economy», «Low Impact Living» and «Open Source» that are linked to the game changers «Financial Crisis», «Climate Change» and «ICT-revolution». They are related to (a) social innovations in ownership, business models, methods of exchange, (b) innovations in life-styles, daily practices and consumer habits and (c) innovations in research, production, sharing of information. After a first theoretical iteration, in-depth case studies are complemented by a metaanalysis of 200 local TSI cases. Data for each local initiative (transnational network) is collected by 5 to 10 (3 to 5) semi-structured qualitative interviews, 10 to 80 (2 to 12) hours of participant observation and the review of 10 to 30 (5 to 10 ) documents (primary and secondary sources, media analysis).

\subsection{IESI}

The project. «ICT-enabled Social Innovation in support to the Implementation of the Social Investment Package» (IESI) strives to support the implementation of the EU Social Investment Packages (SIP) by addressing how ICT-enabled social innovation can support social investment policies. Results enhances understanding on how ICT-enabled social innovation initiatives can contribute to simplifying administrations: better targeting benefits and services (e.g. through simpler procedures, better information or one-stop-shops), improving the management, provision and coordination of services, designing high-quality and cost-effective services meeting the needs of citizens, and supporting access to and take-up of services.

Definition social innovation. According to the project's rational ICT-enabled social innovation is '[a] new configuration or combination of social practices providing new or better answers to social protection system challenges and needs of individuals throughout their lives, which emerges from the innovative use of Information and Communication Technologies (ICTs) to establish new relationships or strengthen collaborations among stakeholders and foster open processes of cocreation and/or re-allocation of public value' (Misuraca $e t$ al., 2015: 42).

Figure 2. IESI Knowledge Map.

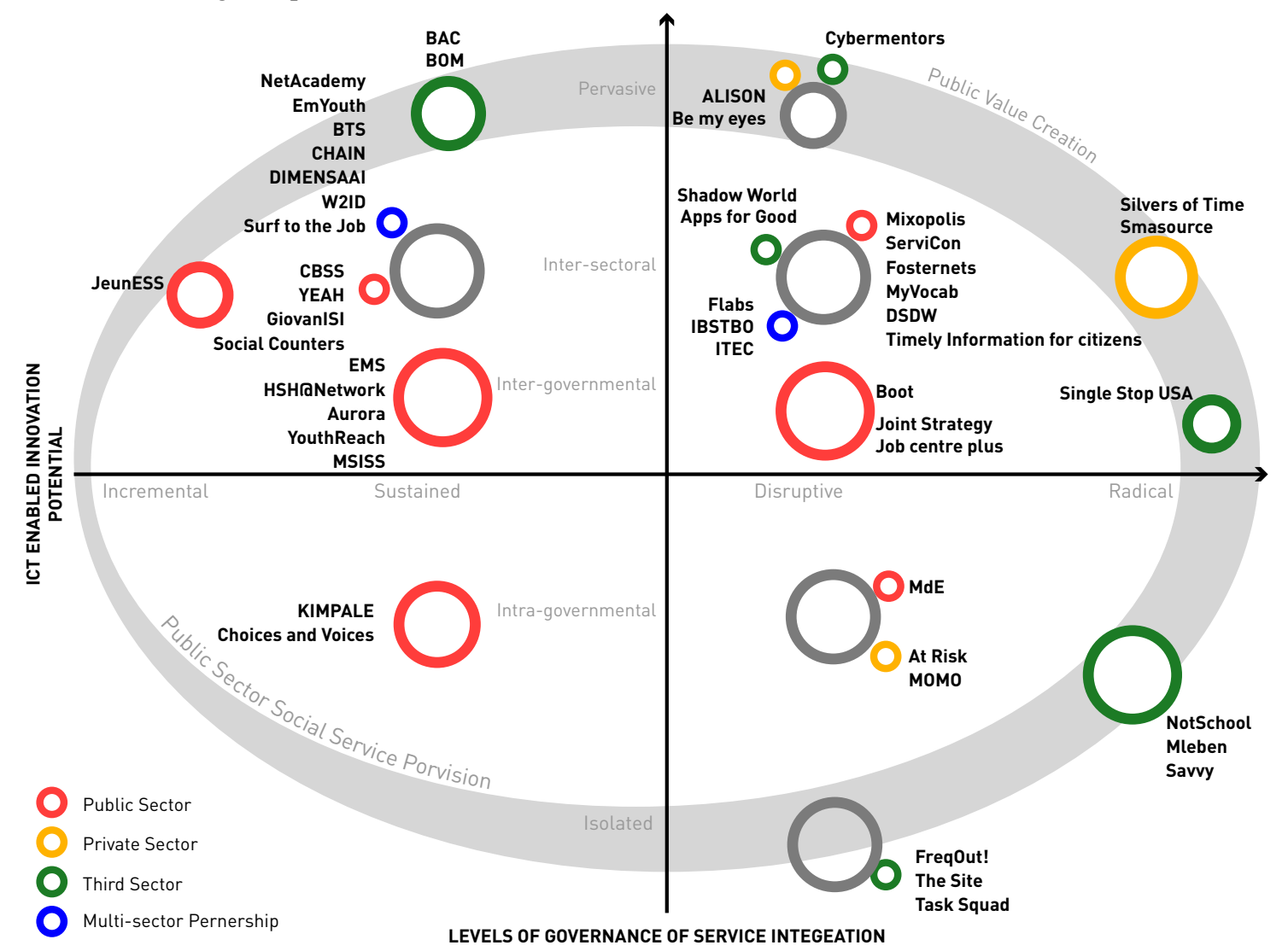

Source: Misuraca (2015). 
Mapping approach. Starting point for the analysis is to address Personal Social Services of General Purpose (PSSGI $^{5}$. Unit of analysis are initiatives that are policy relevant, which aim to simplify/modernise social policies, benefits and/or administrative procedures and service delivery through ICT-enabled innovations (Misuraca et al., 2015). With a focus on EU Member States, initiatives were identified through a review of state of the art and through scanning project databases and other direct sources. Policy relevance, ICT-enabled social innovation and evidence of policy outcomes served as selection criteria. Data was collected through a comprehensive 'template' of 44 variables (qualitative and quantitative) organised in categories such as description data, organisational data, resources, monitoring and evaluation, future prospects, lessons learned and challenges, and information sources. Variables are grouped in three sub-sets, to be collected during different phases: The first sub-set was collected in the analysis of state of the art review phase, the second during the mapping phase and the third will be collect in the case studies phase. Main dimensions of the mapping exercise were the following aspects: (1) typologies of ICTenabled innovation potential (technical / incremental, sustained / organisational, disruptive, and radical), (2) levels of governance (isolated, intra-governmental, inter-sectoral, pervasive), (3) types of social integration (e.g. need-driven/outcome oriented), and (4) elements of social innovation (e.g. funding, organisation). During the first phase of mapping, 100 initiatives were identified of which 50 were included in the mapping process and subsequent analysis.

\subsection{CASI}

The project. Public Participation in Developing a Common Framework for Assessment and Management of Sustainable Innovation (CASI) investigates the scope of sustainable innovation as a societal phenomenon. It enables the elaboration of an assessment framework of sustainable innovation practices, which can be integrated into public policy developments.

Definition of social innovation. CASI utilises a traditional innovation model, where social innovation is one of seven types of innovation. The distinct innovation types are summarised under the term «sustainable innovation».

Mapping approach. CASI's mapping exercise focuses on sustainable innovation cases in EU-28 along three dimensions: (1) 22 HORIZON 2020 topics grouped in three innovation pillars: climate action, resource efficiency and raw material; (2) seven types of innovation: product, service, social, organisation, governance, system and marketing; (3) 22 sectors. Based on desk research in an initial step, 500 cases were nominated, of which the top six cases per country were selected. For each of the six cases an in-

\footnotetext{
5 The following social services are investigated: childcare, education and training, social assistance, social care, social housing, employability, employment, social inclusion/participation, civic engagement, active and healthy ageing and long-term care.
}

depth mapping was conducted through standardized interviews utilizing a theoretically deduced questionnaire.

\subsection{LIPSE}

The project. Learning Innovation in Public Sector Environments (LIPSE) identifies drivers and barriers to successful social innovation in public sector in $11 \mathrm{EU}$ countries and 7 policy sectors. Five building blocks of social innovation in the public sector are investigated: (1) environments, (2) inputs, (3) tools and processes, (4) outcomes, and (5) feedback loops and innovative systems.

Definition of social innovation. LIPSE defines social innovation ' $[. .$.$] as innovation that is related to cre-$ ating new services that have value for stakeholders (such as citizens) in terms of the social and political outcomes they produce' (Lewis et al., 2013: 8).

Mapping approach. LIPSE applied social network analysis to map, analyse and compare the innovation capacity of public sector environments in four European countries, where municipalities built the cases. The mapping focused on two closely intervened aspects: First, institutional environments to study the role of social capital, innovation champions and leadership and second citizens' engagement in public innovation processes. Methods applied are (1) document analysis of the organisational structures of the municipalities, (2) an online administered survey of administrators and politicians, and (3) interviews with community-based innovators. The survey covered the following aspects: innovation environment (e.g. significant innovations in the municipality, barriers and drivers, socio-economic challenges, self-rated innovativeness), networking, social networks and associated resources, leadership for innovation, and background information concerning the respondent. A second mapping exercise focused on the influence of feedback loops, accountability mechanisms and learning processes (FAL) within award winning public organizations (i.e. administrative projects or practices which were recognised as 'best practices') on the sustainability of social innovation in six European countries (van Acker et al., 2015). In particular, national and international awards of excellence, innovation and/or quality in the public sector were screened to map cases. In total 845 cases were collected.

\subsection{SEFORÏS}

The project. Social Enterprise as Force for more Inclusive and Innovative Societies (SEFORÏS) ${ }^{6}$ seeks to understand the potential of social enterprise in EU and beyond to improve social inclusion through greater stakeholder engagement, promotion of civic capitalism and changes to social service provision through (1) investigation of key processes within social enterprises (SE) for delivering inclusion and innovation, and (2) analysing formal and informal institutional contexts in support of SE.

\footnotetext{
${ }^{6}$ Social Entrepreneurs as Lead Users for Service Innovation (SELUSI, 2008-2012) as predecessor of SEFORIS mapped 600 social ventures and the attributes of 500 social entrepreneurs in Europe.
} 
Definition of social innovation. Broadly, SE are understood as organisations that pursue a social mission through the use of market mechanisms, i.e. through generating own revenues to sustain themselves. In accordance with the project's rational, no unique definition of SE was adopted. Rather SEFORÏS refers to the country-specific understandings of SE.

Mapping approach. To expand and enrich understanding of social enterprises, SEFORÏS combines SE field and lab experimentation with in-depth case studies and the collection longitudinal survey data across 9 countries in Europe, Russia and China. Conceptually based on the project's predecessor SELUSI, the mapping follows a three-step procedure: First, 27 in-depth case studies (3 in each country, 236 interviews) were conducted and documented in a qualitative dataset. The cases gather information about governance, finance, innovation, impact and context, which build the 5 core research areas of SEFORÏS. Second, through surveys and standardized telephone interviews, a dataset of 1'000 SE across Europe, Russia and China is collected during the next six months. Third, it is envisaged to link datasets with the Community Innovation Survey.

\subsection{ITSSOIN}

The project. Impact of the Third Sector as Social Innovation (ITSSOIN) investigates the impact of the Third Sector and civic engagement on society. For the purpose of the project Third Sector impact is narrowed down to the priority of social innovation.

Definition of social innovation. Treating social innovation as «quasi-concept», ITSSOIN refers to social innovation as '[...] one of the third sector's primary contributions of social impact. This covers both sides of the reasoning: (1) one of the main social impacts of the third sector is the creation of social innovation [...]; (2) the third sector's social impact arises from social innovation, i.e. social innovation is one of the primary mechanisms that generate social impact' (Anheiner et al., 2014a: 21). Forasmuch, social innovation is understood '[...] as the capacity of non-profit organizations to generate novel ideas, ways and means of doing things, of addressing public and social problems of many kinds' (ITSSOIN, 2015).

Mapping approach. The project's mapping exercise is based on theoretically deduced hypotheses that are investigated empirically by identifying dominant social innovation streams in selected fields. The formulated hypotheses cover (1) organisational properties, (2) effects of volunteering, (3) institutional frameworks, (4) citizens perceptions and (5) media perceptions (Anheier et al., 2014c). In total 20 case studies are conducted in seven fields of analysis, which will result in a crosscountry comparison of roughly 3 countries per selected dominant social innovation in the respective field of activity, by means of «qualitative comparative analysis» (QCA). «Process tracing» is used as method to track phases of the emergence of social innovation and the entities involved. The in-depth analysis of involved entities is expected to allow determining of whether the hy- pothesised characteristics and properties drive the emergence of social innovation in reality. In addition, civic engagement in form of volunteering is explicitly considered, making use of survey data.

\subsection{BENISI}

The project. Acting as a «network of networks», Building a European Network of Incubators for Social Innovation (BENISI) aims to identify and highlight 300 of the most promising, impactful and employmentgenerating social innovations and create conditions for the transfer and scaling of social enterprises. Therewith, it is envisaged to expand the reach and impact of social innovation, and generate positive cascading effects across Europe (BENISI, 2013).

Definition of social innovation. According to BENISI's understanding social innovation refers to '[...] a new idea, product, service or model that simultaneously meets social needs and creates new social relationships or collaborations. Social innovations are not only important for the new specific solutions to societal needs, but they can furthermore impact on society's capacity to innovate' (BENISI, 2015a).

Mapping approach. BENISI's mapping comprises more than 300 cases from around 30 countries. The cases are categorised by six societal trends to which they are referring. As the opportunities for scaling is a leading question in BENISIS's approach, the scaling trajectory is another important criterion for the categorisation of the cases. The approach is based on the theoretically grounded framework by Weber, Kröger \& Lambrich (2012) and distinguishes between four kinds of trajectories, namely (1) capacity-building (scaling alone, no need for adaptation), (2) branching (scaling alone, adaptation necessary), (3) dissemination of knowledge (scaling with partners, no need for adaptation) and (4) affiliation (scaling with partners, adaptation necessary). The single case is characterised by pointing out its social purpose, social impact and innovative character (BENISI 2013b).

\subsection{EFESEIIS}

The project. «Enabling the Flourishing and Evolution of Social Entrepreneurship for Innovative and Inclusive Societies» (EFESEIIS) overall mission is '[t]o produce new knowledge enabling the European people to fully understand the conditions under which social entrepreneurship starts, develops and can contribute effectively and efficiently to solving societal challenges in a sustainable way' (EFESEIIS, 2015). Forasmuch, the project aims to (1) provide advice to stakeholders on how to foster social entrepreneurship and social innovation, (2) elaborate an evolutionary theory of social entrepreneurship, (3) identify features of an enabling eco-system for social entrepreneurship, and (4) identify the «new generation» of social entrepreneurs.

Definition of social innovation. Neither a common definition of social innovation nor of social enterprise is provided. Rather the project draws on the country- 
specific understandings of the terms, which are reflected in the respective country reports.

Mapping approach. EFESEIIS' mapping focuses on in-depth analysis of about 70 pre-selected «New Generation Social Enterprises» from 10 European countries making use of a narrative approach (Benadusi \& Sapienca, 2015). The aim is to explore differences and similarities within and between cases. Data collection techniques comprise desk analysis, dialogic methods and shadowing/participative observation (Benadusi, 2015). Using narrative interviews, the entrepreneur is (a) asked to talk about himself (background, education, style of leadership, professional experiences, relational skills, social capital), (b) provide a snapshot of the organisation (e.g. business model, revenue capacity, sources of income, innovation level etc.), and (c) take a look at the future (e.g. vision, challenges, trends, future growth). Next to the European case studies, five rapid appraisals outside Europe are conducted.

\subsection{Third Sector Impact (TSI)}

The project. The Contribution of the Third Sector to Europe's Socio-economic Development (TSI) aims to create knowledge that will further advance the contributions that the Third Sector and volunteering can make to the socioeconomic development of Europe. Countries covered have been strategically chosen to capture the major regions in Europe that differ significantly with respect to scale, structure and character of the Third Sector.

Definition of social innovation. TSI's main focus lies on the nature of the Third Sector, not on social innovation. However, social innovation is one important aspect of the impact Third Sector organisations might have on their stakeholders and society as a whole. In this context, social innovation is understood as an approach to find new solutions to unattended social problems. By this means, social innovation can initiate and contribute to social change (TSI, 2014).

To define the Third Sector, the project made use of the five criteria 'breadth', 'clarity', 'comparability', 'operationalisability' and 'institutionalisability' (Salmon \& Sokolowski, 2014). According to the TSI consortium, "the third sector, consisting of civil society associations and foundations, volunteers, and other citizen organisations and activities, offers unique renewable and sustainable resources for social and economic problem-solving, democracy, and civic engagement in Europe" (TSI, 2015).

Mapping approach. In order to map current challenges and opportunities of Third Sector Organisations, for each country an online survey will be conducted.
The first survey «What moves the third sector in the Netherlands» was launched in June 2015.

The survey aims at stakeholders of third sector organisations such as volunteers and employees but also participants or users. The survey is structured along five categories, namely (1) well-being and quality of life, (2) social innovation, (3) civic engagement, empowerment, advocacy, community building, (4) economic impacts and (5) human resource impacts. On the basis of the survey results, the most promising approaches to third sector impact assessment ought to be identified (TSI, 2014).

\subsection{DSI}

The project. «Digital Social Innovation» (DSI) aims to define and understand the potential of digital social innovation and to elaborate a living map of organisations that use digital technologies for the social good. More specifically, both the economic and societal potential, and the specific impact and added value of the innovation enabled by the Future Internet, and Digital Social Innovation, are assessed (Bria, 2014).

Definition of social innovation. Digital social innovation is defined as '[...] a type of social and collaborative innovation in which final users and communities collaborate through digital platforms to produce solutions for a wide range of social needs and at a scale that was unimaginable before the rise of Internet-enabled networking platforms' (Bria, 2014: 5). Here, DSI activities and collective awareness platforms are understood as «Digital Commons». Their building and governance ' $[\ldots]$ honours participation, inclusion, empowerment, equal access

Mapping approach. Based on a multi-disciplinary theoretical grounding of the field, a mixed method approach including field-based case studies of DSI organisations and projects, together with quantitative analysis underpinned by open data gathered though a generative European-wide survey was applied. Triangulation was used to compare and corroborate evidence (Bria, 2014). To classify as DSI, organisations and their activities had to meet the following five criteria: (1) generates social impact, (2) adopts new technology trends in a novel way, (3) aims at empowering citizens, (4) demonstrates a clear network effect, and (5) is driven by grassroots or bottom-up initiatives. From the initial list of 100 cases 35 met the above criteria and were analysed by means of in-depth semi-structured interviews. In addition, secondary data was used to understand the position and significance of the organisation. For data collection a generative open online survey was conducted. 
Figure 3. Screenshot DSI CROWDMAP.

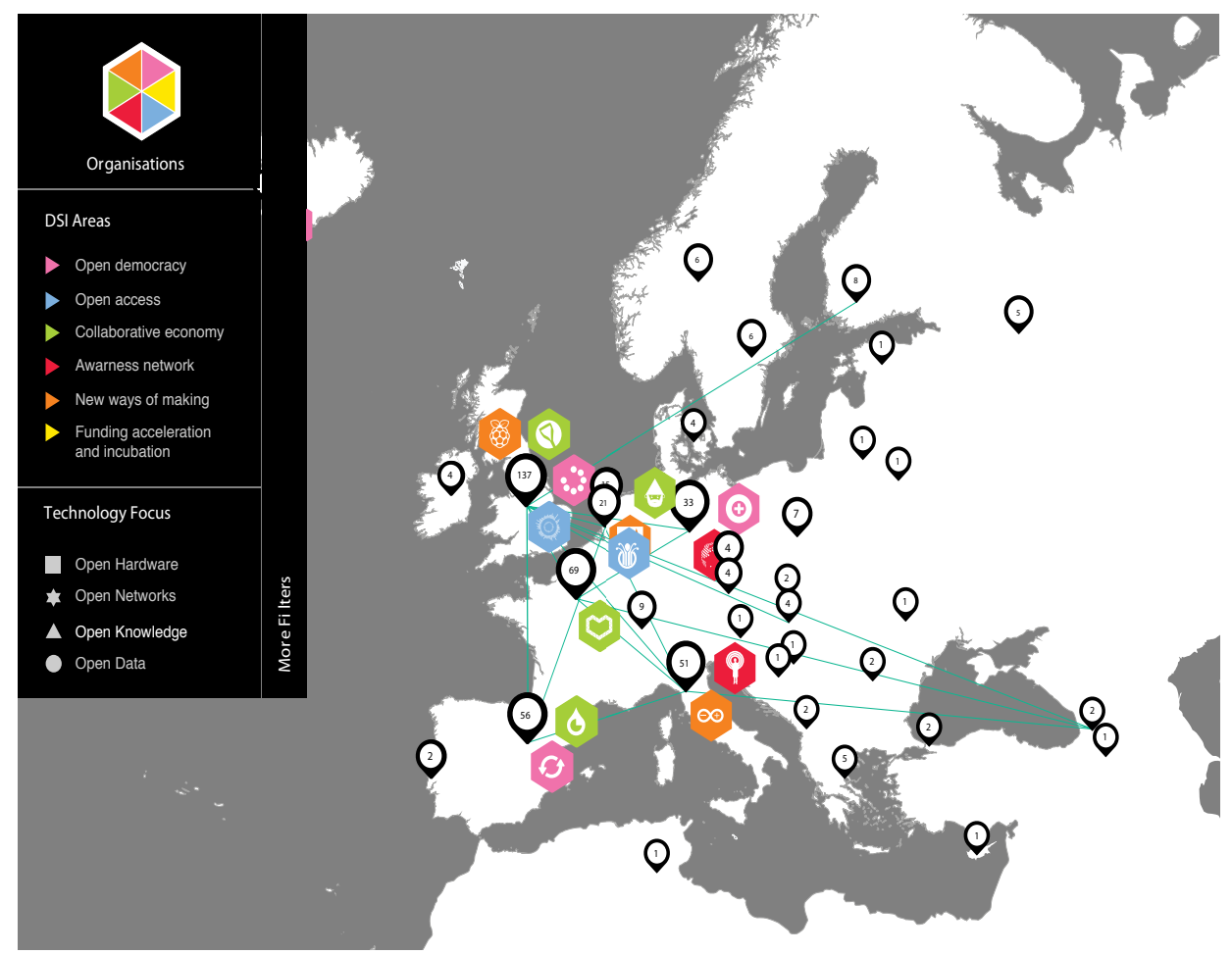

Source: Bria (2015: 11f).

By January 2015 a total of 1'000 DSI organisations and 630 collaborative projects were mapped. Data is categorised by «type of organisation», «type of project», «technology trends», and «areas of society» (Bria, 2015).

\subsection{CITISPYCE}

The project. «Combating Inequalities through Innovative Social Practice of, and for, Young People in Cities across Europe» (CITISPYCE) builds on research that shows the disproportionate impact of the economic crisis on young people across Europe. Against this backdrop, the project strives to investigate the current state of the art and ideas concerning social innovation addressing inequalities faced by young people (16-24), to explore socially innovative practices being developed by and for young people in urban areas.

Definition of social innovation. Within CITISPYCE social innovation are understood as ' $[\ldots]$ addressing social inequalities' drawing on questions such as why, what, who and how (Jubany \& Güell, 2015: 5). More precisely, social innovation refers to '[...] a practice that in innovative ways counteracts/changes the cause of inequalities, affecting young people' (Grander \& Alwall, 2014: 3). Practices are regarded socially innovative as far as they (1) meet new social needs or better meet existing ones, (2) find new ways of meeting social needs which are more effective, efficient and/or sustainable than alternatives, (3) empower people, (4) promote awareness of rights and active citizenship, (5) turn social challenges to opportunities, and (6) increase social capital, trust and capacity to take action.
Mapping approach. Following a potential-oriented approach, in the initial step CITISPYCE mapped the policy frameworks in 10 European cities. Having identified the neighbourhood as an important level, in which inequalities are manifested, their social structure (i.e. composition of population) and infrastructure (i.e. public services) were mapped. For each of the 10 cities two areas were selected. Document analysis was combined with site visits and 15 expert interviews. In total 146 interviews were conducted, focusing on the socio-spatial characteristics of the neighbourhood, the local infrastructure, the relation of infrastructure to inequalities, and incidences of social innovation (Güntner, Gehrke, Seukwa, 2014b). Subsequently, young people's perceptions, experiences and social practices in relation to social inequalities were mapped through interviews and participant observations. In total 607 people participated, 445 interviews were conducted and 26 focus groups organised (Hussain \& Higson, 2014).

\subsection{SocIEtY}

The project. Overall objective of «Social Innovation Empowering the Young for the Common Good» (SocIEtY) is to improve the quality of life of disadvantaged young people through social innovation. Specifically, the project aims to (1) improve the quality of life of disadvantaged young people, (2) identify opportunities to reduce inequalities, and (3) extend and build knowledge and tools in support of the policy goal 'good life for all'.

Definition of social innovation. Within SocIEtY social innovation refers to '[...] new ideas that work in meeting social goals and brings increased social value to 
society' (Rosendal Jensen, 2013: 124). Social value is understood as '[a] combination of absence of focus on profit and the contributions from the volunteers/professionals, makes it possible to create social value. At the same time social value in certain cases can be converted to reduce economic transaction costs' (Rosendal Jensen, 2013: 126).

Mapping approach. Mapping activities within SocIEtY cover two major blocks: First, the analysis of the socio-economic political context within which decisions are made through mapping current policy processes and social support measures in 11 countries, and by a capability-oriented statistical analysis of measures of inequality. Second, the analysis of local social support networks by (1) investigating social practices and mechanisms, (2) collecting young people's aspirations, wants and experiences, and (3) elaborating an experimental participatory research methodology for social innovation. With regard to the latter participatory research by means of regional case studies, it builds upon and deploys the theoretical, conceptual and previous empirical work. Participator research is understood as '[...] practice of reflection in which some questions should be addressed concerning how our research relates to democracy and participation' (Vandekinderen \& Roose, 2014). Pilot workshops with young people, researchers and other stakeholders have been conducted, where concrete methods of investigation have been prepared and discussed.

\subsection{ImPRoVE}

The project. «Poverty Reduction in Europe: Social Policy and Innovation» (IMPROVE) strives to enhance the basis for evidence-based policy making in the areas of poverty, inequality and social innovation in Europe. Research is lead by the questions, (1) how Europe can achieve social cohesion and (2) how social innovation complements, reinforces and modifies macro-level policy and vice versa.

Definition of social innovation. Drawing on The Young Foundation (2006) and Ilie \& During (2012), social innovations are understood as ' $[\ldots]$ innovations that are social in their ends as well as in their means' (Oosterlynck et al., 2013: 2). It is assumed that social innovation '[...] implies a particular view of poverty and social exclusion. [...] poverty and social exclusion are defined in a much broader sense than pure lack of material or financial resources' (ibid).

Mapping approach. ImPRoVE's mapping exercise aims to develop a database of local socially innovative policies and practices that address new and growing inequalities. Particular attention is given to the governance dimension of successful socially innovative policies and actions. More precisely, governance challenges that are rooted in the complex interrelationships between actors, instruments and goals of local forms of social innovation and redistributive policies of the national welfare state are investigated. The focus is on policies and actions that have (successfully or not) experimented with policy mixes, that include socially innovative instruments (e.g. so- cial learning, awareness raising, mobilisation/collective action) and also with multi-level governance. In total, 30 case studies will be conducted covering distinct welfare and governance models, of which nine are already documented. Cases have been sourced in collaboration with SOCIAL POLIS, Eurocities, EUKN and URBACT. Data analysis uses comparative and transdisciplinary methods.

\subsection{TEPSIE}

The project. «Theoretical, Empirical and Policy Foundations for Building Social Innovation in Europe» (TEPSIE) aimed to lay the ground for developing tools, methods and policies as part of the EU strategy for social innovation. Its purpose was to strengthen social innovation's foundation for other researchers, policymakers and practitioners to help advance the field. Hence, TEPSIE mapped the field, reviewed theories, models and methods and identified gaps in existing practices and policies, as well as pointed towards the priorities for future strategies (TEPSIE, 2014).

Definition of social innovation. Within TEPSIE social innovation has been defined as '[...] new solutions (products, services, models, markets, processes etc.) that simultaneously meet a social need (more effectively than existing solutions) and lead to new or improved capabilities and relationships and better use of assets and resources. In other words, social innovations are both good for society and enhance society's capacity to act' (The Young Foundation, 2012: 18).

Mapping approach. According to the project's rational, rather than collecting a large dataset, TEPSIE made use of a case study approach, i.e. case studies were conducted as exemplification of the issue researched. Themes covered among others the state of social economy, citizens' engagement in social innovation, the spread of social innovation as well as online collaboration and the networking tools for social innovation. The mapping of citizens' engagement in social innovation, for example, started with extensive desk research on the distinct methods of engagement along the three theoretically deduced functions of (1) providing information and resources, (2) problem solving, and (3) taking and influencing decisions (Davies \& Simon, 2013; Davies et al., 2012). For each function two methods were identified, for which a case study at global scale (12 in total) was conducted by the means of telephone and face-to-face interviews, using a semi-structured interview guide. For each case the following issues were examined: brief description of the engagement activity, origins including background information, key resources, value of the approach, and outcomes and impact. To investigate the theoretically informed spread of social innovation (beyond organisational growth) focusing on new programmes, practices and organisational structures, 3 in-depth case studies were conducted by means of 8 to 10 interviews per case (Davies, 2014). Four criteria were applied to select cases: (1) involvement of an intermediary in the spread, (2) one global example, one which spread between two countries, and one which spread within the national context, (3) in- 
tervention in the field of education, and (4) feasibility of carrying out the research.

\section{Similarities \& Differences}

The synopsis of mappings summarised in this article illustrates the variety of objects, means and results of the scrutinized mapping processes. The subsequent similarities and differences became apparent.

\subsection{Understanding of Social Innovation}

The 17 investigated projects illustrate a wide bandwidth of understandings of social innovation. Or even more with the words of Jenson and Harrison: 'but in several projects the authors declined the invitation to propose their understanding of social innovation' (European Commission 2013: 15). While there are projects that explicitly do not apply a definition of social innovation for their mapping but try to embrace different notions of this term (e.g. EFESIIS, SEFORIS), others initiate their mapping by a fixed understanding of what counts as a social innovation. Among these, huge differences can be observed. Whilst some (e.g. SIMPACT) put the target group of vulnerable people at the heart of their definition, others (e.g. LIPSE) understand social innovation from a perspective of origin (in the case of LIPSE: public administration) or in the context of entrepreneurship. Meanwhile, for example, SI-DRIVE applies a more abstract and open concept of social innovation and defines SI by the term of 'social practice' (Howaldt et al. 2014). The idea to collect «what counts as a Social Innovation in a specific region» can be found in two mappings opening up the mapping exercise for a multi-notional research.

A quite recent development is the focus on digital technology: DSI and IESI are focused on social innovations that are either initiated by digital means or are using them.

\subsection{Methods of Data Collection}

The prevailing instrument of collecting data for mapping social innovations is the case study, making qualitative research the dominant approach. In the identified case, study-based projects cases are retrieved from repositories - predominantly online databases. Only few projects apply quantitative data, whereas this data is usually complemented by qualitative data, mostly retrieved from case studies. Interviews are the second most frequently used scientific method to collect data for mappings. Only few projects apply other methods such as network analysis, or even tailored instruments such as «Social Innovation Biographies» applied by SIMPACT or the narrative approach developed by EFESEIIS.

\subsection{Mapping Dimensions}

Most of the described mapping endeavours are applying the addressed societal challenges as one mapping dimension. Unemployment, demographic change and edu- cation seem to be the most prominent topics that count as selection criteria. Very explicitly CASI is adopting Horizon 2020's challenges as selection criteria, addressing their research 1:1 to the EU research framework programme. Other mappings apply between 3 and 7 topics as a first dimension of mapping. For the second mapping dimension various criteria can be found; spatial criteria (like in CITISPYCES, LIPSE, DSI or CASI) are employed as well as welfare regimes (e.g. SIMPACT) or criteria referring to the quality, lifecycle stage or spread of the social innovation (e.g. IESI). Most common is the ambition to relate social innovations to a local or regional context (e.g. CITISPYCES, LIPSE, DSI or CASI). This strongly links to the debate on the role of the local context to foster social innovations (Innobasque, 2013).

\section{Conclusion}

Taken together, the identified mapping approaches reveal some gaps in the process of collecting data as well as on the layer of results.

\subsection{Missing Users' Perspective}

The most striking result from our synopsis is the rare orientation of the existing mappings towards the dimension of target groups or users of social innovations. While many of the applied definitions of social innovation comprise specific target groups as a component, the distinct mapping approaches do not actively involve these in the mapping activities. To some extent this is attributable to the tensions between the demands of academia and the needs of, for example, vulnerable or young. As Aldrige (2014: 112) emphasises «[t]his is particular the case in research governance and practice terms when 'top-down' pressure (e.g. from academy, from funders) are often odds with need for 'bottom-up' approach to vulnerable (young) research participants who often require adaptive, more inclusive and sometimes individualistic (case-by-case) qualitative methodological approaches».

SIMPACT, for example, explicitly focuses on «vulnerable» as a target group and mapped them by means of social innovation ID cards, business case studies and biographies. However, no mapping activities were carried out in cooperation with the target group. Instead small-scale stakeholder experiments are conducted with representatives of vulnerable populations to grasp the target groups' view on the economic underpinning of social innovation. Focusing on the «young», CITISPYCE, in contrast, applied ethnographic observation of and in-depth interviews with the target group in the framework of its mapping activities, which delivered valuable insights.

Drawing on such experience, future mappings should to a larger extend apply approaches in which the target groups/users of social innovation are an integral part of research. Such an approach would significantly contribute to a better understanding of (1) target groups' behaviour patterns, demands and problems, (2) how these are met by social innovations, (3) what role the context and framework conditions (e.g. welfare system) play, and (4) 
how to orchestrate target groups in providing innovative solutions. Such insights are expected to fuel the development and spread of tailored social innovations across Europe.

\subsection{Missing Impact Dimension}

Although many of the identified mapping approaches claim themselves to be explorative, seldom the mapping activities include reflections on social innovations' impact. As an exemption IESI indicates a first attempt to map features as «sustained» or «isolated» social innovations. Likewise, SIMPACT through its Social Innovation Biographies tried to capture the innovations impact. The missing impact assessment in the actual mapping approaches is not at least attributable to the lack of measures that reflect the multiplicity of social innovation and related impact (e.g. social, economic, political, for the target group/the society). However, the impact dimension plays a pivotal role for social innovators, for example when it comes to finance, as well as for policy makers (e.g. legitimacy) or investors.

\subsection{Generalisation from Case Studies}

As has been shown in the previous sections, the majority of mapping efforts apply qualitative methods and in particular case studies for data collection resulting in small-N (mostly below 300 cases). We find the collec- tion of quantitative data to be an exception in recently finalised and ongoing mapping activities. Combining qualitative and quantitative data in mixed method research designs by means of triangulation has the potential to enhance the validity of the data collected. Moreover, it is apparent that a cross-project comparison of case studies is difficult, if not impossible due to the various understandings of social innovation and methods applied.

Notwithstanding the above, many projects establish strong links between the production of theory, empirics and tools. This in turn raises the question of generalizability. Concerning theory development, case studies are often criticised based on the assumption that their findings are not generalizable to other settings. On the contrary it is argued that case studies are most appropriate to study the «how» and "why», in particular in the form of multiple case designs (Tsang, 2014; Yin, 2014). This aspect is crucial to social innovation which, so far lacks a common theoretical grounding.

To overcome the outlined limitations of projectspecific case studies, from the authors perspective it would be worthwhile to undertake the attempt to build a unique case study database based on openly accessible data. This would on the one hand enhance the possibilities of generalisation and on the other contribute to a more efficient use of the data collected. 


\section{References}

Aldrige, J. (2014). Working with vulnerable groups in social research: dilemmas by default and design. Qualitative Research, 14(1): 112-130.

Anheier, H. K., Krlev, G.; Preuss, S.; Mildenberger, G.; Bekkers, R.; Mensink, W.; Bauer, A.; Knapp, M.; Wistow, G.; Hernandez, A. and Bayo, A. (2014a). Social Innovation as Impact of the Third Sector. A deliverable of the project: "Impact of the Third Sector as Social Innovation" (ITSSOIN), European Commission - 7th Framework Programme, Brussels: European Commission, DG Research.

Anheier, H. K., Krlev, G., Preuss, S., Mildenberger, G. and Einarsson, T. (2014b). Theory and empirical capturing of the third sector at the macro level. A deliverable of the project: "Impact of the Third sector as Social Innovation" (ITSSOIN), European Commission - 7th Framework Programme, Brussels: European Commission, DG Research.

Anheier, H. K., Krlev, G., Preuss, S., Mildenberger, G., Bekkers, R. and Lund, A. B. (2014c). Socio-economic impacts of the Third Sector - Considerations \& Hypotheses. ITSSOIN Research Brief. A deliverable of the project: "Impact of the Third Sector as Social Innovation" (ITSSOIN), European Commission - 7th Framework Programme, Brussels: European Commission, DG Research.

Avelino, F., Wittmayer, J., Haxeltine, A., Kemp, R., O’Riordan, T., Weaver, P., Loorbach, D. and Rotmans, J. (2014). Game-changers and Transformative Social Innovation. The Case of the Economic Crisis and the New Econo$m y$. TRANSIT working paper, TRANSIT: EU SSH.2013.3.2-1 Grant agreement no: 613169.

Beckert, J. (2010). How Do Fields Change? The Interrelations of Institutions, Networks, and Cognition in the Dynamics of Markets. Organization Studies, 31(5): 605-627.

Benadusi, M. (2015). WP5 - New Generation Social Enterpreneurs. Available at: https://prezi.com/qhwdiwadg6vo/wp5-new-generation-social-enterpreneurs (11/06/2015)

Benadusi, M. and Sapienza, R. (2015). WP5 - Case Studies Guide. Operative Manual, Version 14/06/2015.

- (2015). Project Summary. Accessible at: http://www.benisi.eu/project-summary (11/06/2015).

- (2013a). Building a European Network of Incubators for Social Innovation. Accessible at: www.benisi.eu/sites/default/files/brochure benisi 1.pdf $(11 / 06 / 2015)$.

- (2013b). Building a European Network of Incubators for Social Innovation. Accessible at: http://www.benisi.eu/sites/default/files/ppt_benisi_2.pdf (10/07/2015).

Bria, F. (2014). Digital Social Innovation. Interim Report. A deliverable of the project "Digital Social Innovation". Brussels: European Commission, DG Connect.

- (2015). Growing a Digital Social Innovation Ecosystem for Europe. DSI Final Report. A deliverable of the project "Digital Social Innovation". Brussels: European Commission, DG Connect.

Davies, A. (2014). Spreading Social Innovations - A Case Study Report. A deliverable of the project: "The theoretical, empirical and policy foundations for building social innovation in Europe" (TEPSIE), European Commission 7th Framework Programme, Brussels: European Commission, DG Research.

- and Simon, J. (2012). Citizen engagement in social innovation - a case study report. A deliverable of the project: "The theoretical, empirical and policy foundations for building social innovation in Europe" (TEPSIE), European Commission - 7th Framework Programme, Brussels: European Commission, DG Research.

- Simon, J., Patrick, R. and Norman, W. (2012). Mapping citizen engagement in the process of social innovation. A deliverable of the project: "The theoretical, empirical and policy foundations for building social innovation in Europe" (TEPSIE), European Commission - 7th Framework Programme, Brussels: European Commission, DG Research.

EFESEIIS (2015). About. Accessible at: http://www.fp7-efeseiis.eu/about (11/06/2015)

Grander, M. and Alwall, J. (2014). WP4 Final Report Malmö. A deliverable by the project "Combating Inequalities through Innovative Social Practices of and for Young People in Cities across Europe". Malmö: Malmö University.

Güntner, S., Gehrke, A.-M. and Seukwa, L. H. (2014a). Policy Frameworks to tackle social inequalities experienced by young people in 10 cities across Europe. A deliverable by the project "Combating Inequalities through Innovative Social Practices of and for Young People in Cities across Europe". Hamburg: HWA.

- (2014b). Neighbourhoods and social infrastructures as spaces of reproducing, mitigating or counteracting social inequalities in 10 European cities. A deliverable by the project "Combating Inequalities through Innovative Social Practices of and for Young People in Cities across Europe". Hamburg: HWA.

Houghton Budd, Ch,, Naastepard, C. W. M. and van Beers, C. (2015). Introduction. In: Houghton Budd C., Naastepad R. \& van Beers C. (Eds.): Report on Institutions, Social Innovation \& System Dynamics from the Perspective of the Marginalised, Deliverable D1.1, CRESSI Project, Chapter 1.

Howaldt, J., Kopp, R. and Schwarz, M. (2015). On the theory of social innovations: Tarde's neglected contribution to the development of a sociological innovation theory.. Weinheim : Beltz Juventa, 2015. URN: http://nbnresolving.de/ urn:nbn:de:0168-ssoar-419633

- . et al. (2014). Theoretical Approaches to Social Innovation - A Critical Literature Review. A deliverable by the project: "Social Innovation: Driving Force of Social Change" (SI-DRIVE). Dortmund: Sozialforschungsstelle. 
Hussain, A. and Higson, H. (2014). WP4 Comparative Report of "Fieldwork II". A deliverable by the project "Combating Inequalities through Innovative Social Practices of and for Young People in Cities across Europe". Aston: University of Aston.

Ilie, E. and During, E. (2012). An analysis of social innovation discourses in Europe. Concepts and Strategies of Social Innovation. Alterra: This is how we do it! \#A.

Innobasque (ed.) (2013). RESINDEX. Regional Social Innovation Index. A regional index to measure social innovation. Accessible at:

ITSSOIN (2015). The Project. Accessible at: http://itssoin.eu/the-project (11/06/2015).

Jenson, J. and D. Harrison (2013). Social innovation research in the European Union. Approaches, findings and future directions. European Commission (ed), Policy Review, Brussels: Publication Office of the European Union.

Jubany, O. and Güell, B. (2015). Menu of Social Innovation Practices (D5.1) \& Interim Workshop Report (D5.2). A deliverable by the project "Combating Inequalities through Innovative Social Practices of and for Young People in Cities across Europe". Barcelona: University of Barcelona.

Lewis, J. M., Ricard, L. M., Klijn, E.-H., Grotenbreg, S., Ysa, T., Albareda, A. and Kinder, T. (2013). Innovation environments and innovation capacity in the public sector. Research paper no. 1 of the LIPSE Project.

Misuraca, G., Colombo, C., Radescu, R. and Bacigalupo, M. (2015). Mapping and analysis of ICT-enabled social innovation initiatives promoting social investment. In: Integrated approaches to the provision of Social Services, European Commission's Joint Research Centre, Institute for Prospective Technological Studies, JRC Technical Reports Series.

Mann, M. (2013). The Sources of Social Power. Vol. 4, Globalizations, 1945 - 2011. Cambridge: Cambridge Univ. Press.

Mulgan, G., Tucker, S. and Wilkie, N. (2006). Social Silicion Valleys. A manifesto for social innovation: what it is, why it matters and how it can be accelerated. London: The Basingstone Press

Nicholas, A. and Ziegler, R. (2015). An Extended Social Grid Model for Study of Marginalization Processes and Social Innovation. In: Houghton Budd C., Naastepad R. \& van Beers C. (Eds.): Report on Institutions, Social Innovation \& System Dynamics from the Perspective of the Marginalised, Deliverable D1.1, CRESSI Project, Chapter 2 .

Oosterlynck, S., Kazepov, Y., Novy, A., Cools, P., Barberis, E., Wukovitisch, F., Sarius, T. and Leubolt, B. (2013). The butterfly and the elephant: local social innovation, the welfare state and new poverty dynamics. ImPRovE Discussion Paper No. 13/03. Antwerp: Herman Deleeck Centre for Social Policy - University of Antwerp.

Rosendal Jensen, N. (2013). Social Innovation and Capability Approach. In: Otto, H.-U. (ed), Final Conceptual Report "Inequalitiy, Disadvantage, Social Innovation and Participation", Deliverable 2.2 by the project "Social Innovation | Empowering the Young for Common Good", pp. 120-146. Bielefeld: Bielefeld University.

Salmon, L. A. and Sokolowski, W. (2014). The Third Sector in Europe: Towards a Consensus Conpetualisation. TSI Working Paper Series No. 2. Seventh Framework Programme (grant agreement 613034), European Union. Brussels: Third Sector Impact.

SEFORÏS (2015). First Highlights of In-depth Study of 27 Social Enterprises. Accessible at: http://www.seforis.eu/en/news/detail/first-highlights-of-in-depth-study-of-27-social-enterprises (11/06/2015).

Søgaard Jørgensen, M. et al. (2014). Methodological guidelines for case studies Batch 1. Deliverable n. 4.1 of TRANSIT project.

TEPSIE (2014). Social Innovation Theory and Research: A Summary of Findings from TEPSIE. A deliverable of the project "The theoretical, empirical and policy foundations for building social innovation in Europe" (TEPSIE), European Commission - 7the Framework Programme. Brussels: European Commission, DG Research.

Terstriep, J., Kleverbeck, M., Deserti, A. and Rizzo, F. (2015). Comparative Report on Social Innovation across Europe. Deliverable D3.2 of the project «Boosting the Impact of SI in Europe through Economic Underpinnings» (SIMPACT), European Commission - 7th Framework Programme, Brussels: European Commission, DG Research \& Innovation. (forthcoming)

The Young Foundation (2012). Social Innovation Overview. A deliverable of the project 'The theoretical, empirical and policy foundations for building social innovation in Europe' (TEPSIE), European Commission - 7th Framework Programme, Brussels: European Commission, DG Research.

Tsang, E. W. K. (2014). Generalizing from Research Findings: The Merits of Case Studies. International Journal of Management Reviews, 16(): 369-383.

TSI (2014). Impacts of Third Sector Organisations' Activities. TSI Background Note N. 1. Available at: http://thirdsectorimpact.eu/site/assets/uploads/consultations/impact-show-differencemakes/Consultations_Impact1_Background_FINAL.pdf (10/07/2015)

- (2015). About Third Sector Impact. Available at: http://thirdsectorimpact.eu/the-project (11/06/2015)

Van Acker, W. et al. (2015). Mapping and Analysing the Recommendations of Ombudsmen, Audit Offices and Emerging Accountability Mechanisms. Research report (WP3) of LIPSE Project.

Vandekinderen, C. and Roose, R. (2014). A common framework for particpative research in local Youth Policy from Capability perspective. Deliverable 4.3 by the project "Social Innovation | Empowering the Young for Common Good". Ghent: Ghent University. 
Weber, C., Kröger, A. and Lambrich, K. (2012). 'Scaling Social Enterprises - A theoretically grounded Framework', Frontiers of Entrepreneurship Research, vol. 32, no. 19, Article 3. Available at: http://digitalknowledge.babson.edu/fer/vol32/iss19/3 (10/07/2015)

Yin, R. K. (2014). Case Study Research: Design and Methods. $5^{\text {th }}$ edition, London: Sage Publications. 